\title{
PRESERVAÇÃO E EDUCAÇÃO AMBIENTAL NA PERSPECTIVA DE UMA COMUNIDADE UNIVERSITÁRIA
}

\author{
Sara Barroso de Oliveira Almeida ${ }^{1}$ \\ Luiz Di Souza ${ }^{2}$ \\ Vinícius Patrício dos Santos Caldeira ${ }^{3}$
}

Resumo: Conhecer a percepção ambiental da sociedade é estratégico para melhorar a relação homem-natureza. Assim, objetivamos investigar a percepção da comunidade acadêmica da UERN, em Mossoró (RN), sobre a preservação do meio ambiente e a Educação Ambiental (EA). Submeteram-se 373 discentes, 48 docentes e 75 servidores a um questionário eletrônico autoaplicável, com dados analisados pelo teste $T$ de student. A maioria reconheceu a importância da preservação ambiental e a urgência em defendêla e demonstrou boa aceitação em relação às ações de EA. Porém, a concretização desta percepção é essencial à preservação ambiental.

Palavras-chave: Percepção Ambiental; Universidade; Rio Grande do Norte.

Abstract: Knowing the environmental perception of society is strategic to improve the man-nature relationship. Thus, we aimed to investigate the perception of the academic community of UERN, in Mossoró (RN, Brazil), about the preservation of the environment and Environmental Education (EE). A total of 373 students, 48 teachers and 75 employees were submitted to a selfadministered electronic questionnaire, with data analyzed by Student's t-test. Most of them recognized the importance of environmental preservation and the urgency to defend it and showed good acceptance towards EE actions. However, the realization of this perception is essential to environmental preservation.

Keywords: Environmental Perception; University; Rio Grande do Norte.

\footnotetext{
1Universidade do Estado do Rio Grande do Norte. E-mail: sarabarroso33@hotmail.com, Link para o Lattes: http://lattes.cnpq.br/6583432012542542

2Universidade do Estado do Rio Grande do Norte. E-mail: souzaluizdi@gmail.com. Link para o Lattes: http://lattes.cnpq.br/0589648773241934

3 Universidade do Estado do Rio Grande do Norte. E-mail: viniciuscaldeira@uern.br. Link para o Lattes: http://lattes.cnpq.br/8674282771546269
} 


\section{Introdução}

A crise ambiental vigente decorre principalmente da degradação oriunda das ações antrópicas. Essas práticas derivam, dentre outros fatores, das percepções inadequadas sobre a importância dos ecossistemas e sobre o dever de sua preservação. Para Leff (2009), o saber ambiental transforma as visões de mundo e a relação entre o conhecimento e as ações na sociedade.

O comprometimento de toda a sociedade com a substituição de práticas ambientalmente nocivas é um desafio a ser enfrentado para a conquista da almejada sustentabilidade. Segundo Fernandes et al. (2004), uma das dificuldades para a proteção dos espaços naturais reside nas diferentes percepções dos indivíduos, oriundos de diversas culturas e grupos socioeconômicos, acerca dos valores que regem o tema. No intuito de compreender o comportamento humano em face à natureza, Tuan (2015) define o termo "percepção" como: "a resposta dos sentidos aos estímulos externos, bem como, a atividade proposital, na qual certos fenômenos são claramente registrados, enquanto outros retrocedem para a sombra ou são bloqueados." Outra definição formal do termo é expressa no dicionário Michaelis de língua portuguesa, em que a percepção aparece como a "capacidade de distinguir por meio da mente ou da inteligência" ou ainda como "qualquer sensação física manifestada através da experiência" (MICHAELIS, 2020).

Desse modo, o estudo da percepção ambiental é um importante recurso para a compreensão das diferentes visões sobre o meio ambiente. Esse conhecimento possibilita o direcionamento da Educação Ambiental (EA) para a construção de valores que produzam ações benéficas à presente realidade ambiental. Ruppenthal et al. (2018) enfatizaram a importância do estudo da percepção ambiental na evolução dos processos educativos. Para os autores, tais processos devem considerar o sujeito em sua complexidade, compreendendo as diversidades de percepções, para tratar com profundidade e inteireza as questões relativas ao meio ambiente. No mesmo eixo, Dill e Carniatto (2020) enfatizam que "ao propor projetos relacionados à EA, é necessário, primeiramente, conhecer as concepções de meio ambiente dos atores envolvidos na atividade".

Observar as lacunas e divergências de entendimentos sobre o meio ambiente em uma universidade é propiciar um olhar sobre como a EA vem repercutindo sobre indivíduos em formação de nível superior e como pode ser aperfeiçoada para cumprir seu papel na transformação da sociedade. A evolução da percepção ambiental beneficia não só o meio ambiente, mas também as esferas sociais e econômicas, visto que cidadãos conscientes tendem a aderir a práticas sustentáveis, como a reciclagem, a redução dos desperdícios e da geração de resíduos, que são importantes meios para a promoção da saúde pública e para a redução das desigualdades sociais.

Assim, este trabalho foi desenvolvido com o objetivo de compreender a percepção ambiental da comunidade da Universidade do Estado do Rio 
Grande do Norte (UERN), na cidade de Mossoró/RN. Tal estudo justifica-se pela necessidade de incentivo à EA no estado e pelo reconhecimento do importante papel dessa instituição de ensino superior (IES) na formação do conhecimento da comunidade regional.

\section{Metodologia}

Para o desenvolvimento deste estudo, foram realizadas as seguintes etapas: elaboração do questionário de pesquisa e aplicação a uma amostra restrita a título de pré-teste; aperfeiçoamento do questionário e da metodologia previamente proposta; aplicação do formulário à comunidade acadêmica da UERN, em Mossoró/RN; tratamento estatístico dos dados.

Esta pesquisa é classificada, quanto à abordagem, como quantitativa, pois emprega instrumentos objetivos de análise das compreensões e atitudes da comunidade pesquisada em relação ao meio ambiente, como os questionários estruturados e as escalas graduadas, suscetíveis de posterior mensuração e validação estatística (SAMPIERRE et. al., 2014). Quanto ao alcance, esta pesquisa é exploratória, busca investigar um aspecto ainda pouco estudado, a saber, a percepção ambiental de uma determinada comunidade (SAMPIERRE et. al., 2014). Quanto à natureza, é aplicada por oferecer subsídios ao desenvolvimento de ações educativas sobre o meio ambiente dentro e fora da universidade em análise.

\section{Elaboração do formulário eletrônico de pesquisa e pré-teste}

O formulário de pesquisa foi primeiramente elaborado e dividido em três módulos: o primeiro correspondia à classificação dos participantes, segundo os critérios de categoria funcional, sexo, faixa etária, renda familiar, rede de ensino de origem e área de formação acadêmica. O segundo era o de percepção ambiental, em que as sentenças propunham afirmações de teor verdadeiro ou falso e cinco alternativas de respostas em uma escala de Likert com pontuações variando de "1" (discordo totalmente) a " 5 " (concordo totalmente). O terceiro correspondia a um questionário sobre práticas cotidianas relacionadas direta ou indiretamente ao meio ambiente, com três possibilidades de respostas, a saber: "sim", "não" e "talvez".

Antes de ser aplicado, este estudo foi submetido e aprovado pelo Comitê de Ética em Pesquisa - CEP, sob parecer no 3.694.539, CAAE: 20554619.6.0000.5294. O grau de consistência interna do questionário foi calculado por meio do coeficiente alfa de Cronbach, com o uso do Excel ${ }^{\circledR}$ (ID: 02260-018-0000106-48304).

O formulário, então, elaborado foi aplicado a título de pré-teste aos discentes de graduação da Faculdade de Ciências Exatas e Naturais - FANAT, da UERN, em Mossoró, sendo 78 estudantes, com faixa etária predominante de 18 a 24 anos $(93,6 \%)$.

revista brasileira educação ambiental 
Concluída a fase de pré-teste, observou-se a necessidade de modificar o formulário de pesquisa. O módulo de percepção ambiental passou a incluir enunciados com alternativas textuais de respostas, para que os participantes assinalassem a mais coerente com o próprio ponto de vista além daqueles previamente postos na primeira versão. O terceiro módulo passou a abordar enunciados com situações hipotéticas, relacionadas ao meio ambiente em que os participantes deveriam posicionar-se, em uma escala de "0" a "10", sobre a probabilidade de aderir ou não a elas.

Para aumentar a confiabilidade do instrumento de pesquisa, previamente calculada pelo coeficiente alfa de Cronbach, observou-se a necessidade de aumentar o número de enunciados e a variabilidade da amostra. Essas modificações foram inseridas no formulário eletrônico aplicado à comunidade acadêmica da UERN, em Mossoró, considerando-a composta pelos docentes, discentes e servidores técnico-administrativos.

\section{Caracterização do universo e da amostragem da pesquisa}

Esta pesquisa teve como público-alvo a comunidade da Universidade do Estado do Rio Grande do Norte - UERN nas unidades sediadas em Mossoró-RN. Além do campus central em Mossoró, a UERN conta com cinco campi avançados nas cidades de Natal, Pau dos Ferros, Caicó, Assú e Patu, alcançando todas as regiões do estado. Somando-se a Universidade Federal do Rio Grande do Norte - UFRN, a Universidade Federal Rural do Semi-Árido - UFERSA, o Instituto Kennedy e o Instituto Federal do Rio Grande do Norte IFRN, a UERN integra o conjunto de instituições públicas de ensino superior no estado. Assim, estas IES oportunizam o acesso da população de diferentes localidades e de diversos contextos socioeconômicos à educação superior, sendo importantes meios para a disseminação do conhecimento e para a redução das desigualdades regionais.

Entre os municípios onde os campi universitários da UERN se fazem presentes, Mossoró é o que sedia o centro administrativo da IES, pois abriga os prédios da reitoria e das pró-reitorias universitárias e o que concentra 0 maior número de faculdades e cursos. Situadas em Mossoró estão: a faculdade de ciências econômicas; a faculdade de serviço social; a faculdade de letras e artes; a faculdade de ciências exatas e naturais; a faculdade de educação; a faculdade de direito; a faculdade de ciências da saúde; a faculdade de enfermagem; a faculdade de educação física e a faculdade de filosofia e ciências sociais.

De acordo com a página "UERN em Números" do portal da UERN, em Mossoró, há 5.087 discentes matriculados, 458 docentes e 467 servidores técnico-administrativos (UERN, 2020). Esses números representam, respectivamente, $59 \%$ dos discentes; $58 \%$ dos docentes e $74 \%$ dos servidores técnico-administrativos de toda a instituição. 
A definição do número mínimo estatisticamente significativo de participações para cada estrato, considerando o nível de confiança de $95 \%$, ou seja, dois desvios-padrão e, admitindo-se erro máximo de $5 \%$, obedeceu à fórmula de Gil (2008, p. 97) para populações finitas:

em que,

$$
\mathrm{n}=\frac{\alpha^{2} \cdot p \cdot q \cdot N}{e^{2}(N-1)+\alpha^{2} \cdot p \cdot q}
$$

$n=$ Tamanho da amostra

$a^{2}=$ Nível de confiança escolhido, expresso em número de desvios-padrão

$p=$ Percentagem com a qual o fenômeno se verifica

$q=$ Percentagem complementar

$N=$ Tamanho da população

$\mathrm{e}^{2}=$ Erro máximo permitido.

\section{Análise estatística dos dados}

Os dados obtidos foram analisados estatisticamente por meio do teste $T$ de student com o software $\operatorname{Exce}^{\circledR}{ }^{\circledR}$, em que foram comparadas as médias das respostas dos participantes das três categorias funcionais, dos diferentes sexos e faixas etárias para observar se havia diferenças significativas entre suas percepções ambientais.

\section{Resultados e Discussão}

\section{Consistência interna do instrumento de coleta de dados}

O cálculo do coeficiente alfa de Cronbach para o instrumento de coleta de dados definitivo, reformulado após o pré-teste, resultou 0,729 , considerado como sendo de consistência substancial por Landis e Koch (1977). Esse índice representa a alta confiabilidade do instrumento utilizado para a obtenção dos dados pretendidos e das conclusões deles decorrentes.

\section{Aplicação do instrumento de pesquisa à comunidade da UERN em Mossoró}

Aplicando-se a fórmula de Gil (2008), descrita na eq.1 para o cálculo da amostra estatisticamente significativa para cada estrato da população (docentes, servidores técnicos e discentes), considerando-se as variáveis $p$ e $q$ de valores iguais a 0,5 ; constatou-se que o número mínimo de respondentes, por estrato, seria: 375 discentes, 220 servidores técnico-administrativos e 215 professores. 
A experiência de conduzir a pesquisa eletronicamente apresentou a vantagem de permitir o alcance de todo o universo amostral a partir do envio dos formulários para os endereços de e-mail institucional. Por outro lado, a baixa taxa de retorno foi uma limitação encontrada nesta modalidade de pesquisa. Responderam ao formulário: 393 discentes, 48 docentes e 75 servidores técnicos, correspondendo respectivamente ao percentual de $7,7 \%$, $10,9 \%$ e $15,8 \%$ de cada estrato amostral. Desses, 304 eram mulheres e 212 homens, correspondendo a, respectivamente $59 \%$ e $41 \%$ do universo amostral. A maioria dos voluntários possui faixa etária entre 18 e 34 anos $(77,56 \%)$, seguida da faixa de 35 a 44 anos (13,54\%).

Pinheiro e Silva (2004, p. 5) discutem a dificuldade de obtenção de retorno em pesquisas eletrônicas:

Em termos de percentagens de taxas de retorno de inquéritos [eletrônicos] que não são preenchidos, Bravo (2001, p.320) refere uma taxa que ronda os $40 \%$ e Alreck (1995, p.35) parte de uma taxa de $30 \%$ como sendo uma taxa de retorno rara. Para este autor uma taxa normal andará pelos 5\% a 10\%.

Diante da baixa taxa de retorno aos formulários encaminhados via emails institucionais, procedeu-se a sua distribuição por meio de links nas redes sociais. Essa iniciativa resultou em aumento dos números de respostas, especialmente por parte dos discentes, que foi o único grupo amostral que atingiu o quantitativo estatisticamente significativo, segundo a eq.1.

Embora o número de participações dos demais estratos (servidores técnicos e docentes) não tenha atingido o mínimo considerável como estatisticamente representativo, sua análise segue parâmetros aceitáveis por corresponder ao percentual esperado de respostas para pesquisas eletrônicas autoaplicáveis. Torrini (2016) reconhece a faixa entre $10 \%$ a $30 \%$ de respostas a pesquisas on-line como aceitável pela literatura, em virtude das dificuldades encontradas nesta modalidade de coleta de dados, entre as quais menciona: a impessoalidade da abordagem; eventuais falhas nas redes de internet ou inacessibilidade do respondente aos recursos de informática e a possibilidade de algumas pessoas não concluírem 0 preenchimento do formulário. Vasconcelos - Guedes e Guedes (2007) relataram a baixa adesão de professores universitários aos questionários distribuídos eletronicamente em comparação com os questionários em papel. Essa constatação condiz com o fato de que os docentes representaram a categoria com menor índice de participação nesta pesquisa.

\section{Percepção sobre a importância da preservação do meio ambiente}

O primeiro enunciado do módulo de percepção ambiental requeria que 
melhor correspondesse à sua opinião sobre a importância da preservação do meio ambiente, considerando o seguinte enunciado: "Em sua opinião, a preservação do meio ambiente...". As respostas dos participantes agrupados por categorias funcionais, sexo e idade, com alternativas designadas nessa discussão pelas letras "A", "B", "C" e "D", estão apresentadas na Figura 1.

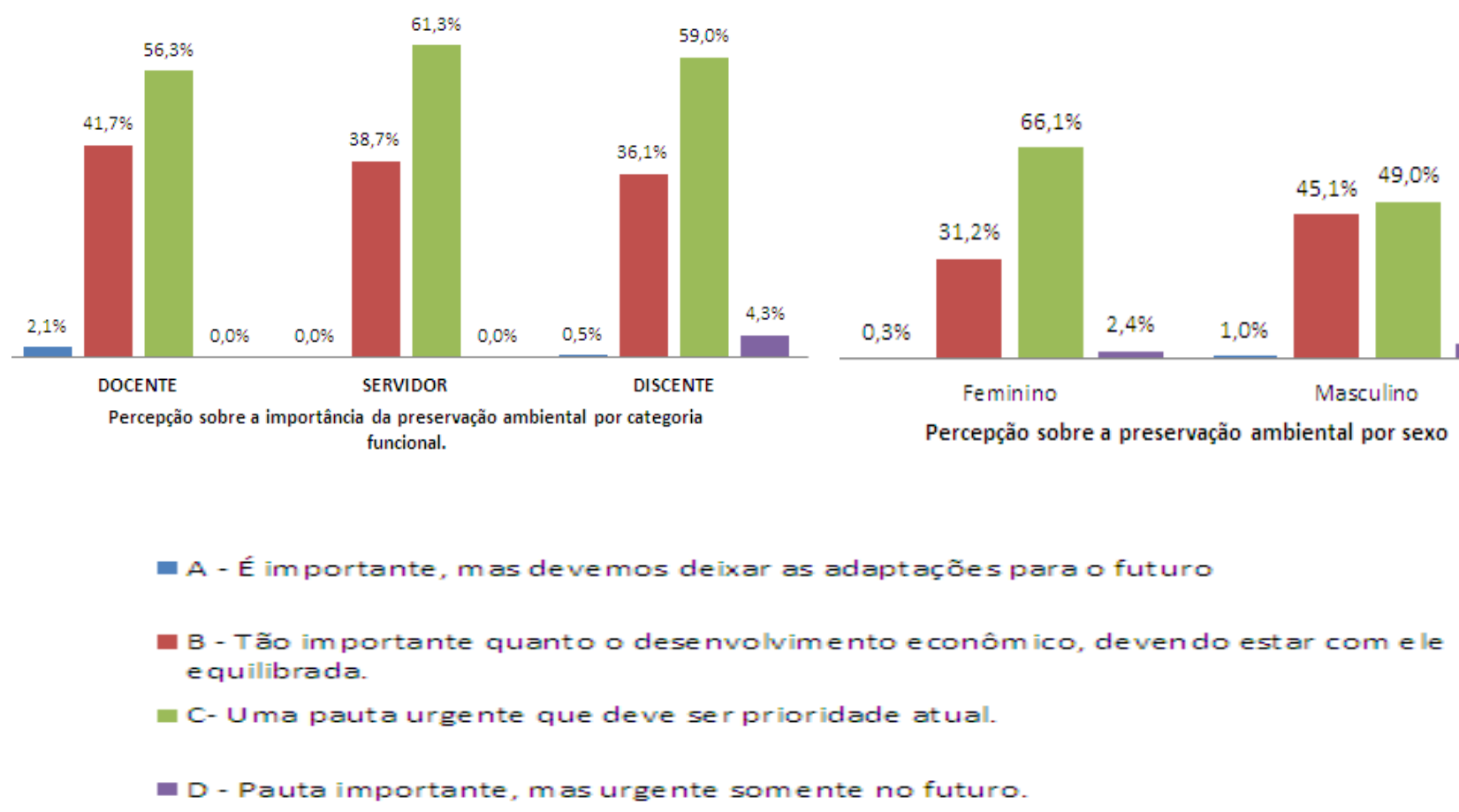

Figura 1: Respostas da comunidade acadêmica da UERN de Mossoró, agrupada por categoria funcional (à esquerda) e sexo (à direita), sobre a importância da preservação ambiental aplicada no questionário definitivo em 2020, em termos percentuais.

Diante dessa questão, observou-se que os discentes, os docentes e os servidores técnicos administrativos apresentaram percepções semelhantes, pois a maioria de todas as categorias funcionais assinalou o item "C", afirmando ser a preservação do meio ambiente uma pauta urgente e prioritária na sociedade atual. Esse reconhecimento é importante, mas deve ser acompanhado de ações eficazes para a plena defesa do meio ambiente.

A segunda alternativa mais aceita foi a que equiparou a relevância da preservação ambiental com o desenvolvimento econômico e defendeu 0 equilíbrio entre os dois fatores. Comparando-se estatisticamente as médias das respostas das diferentes categorias por meio do teste $T$ de student, observouse que não houve diferença significativa $(t=0,138)$ entre as percepções dos docentes e dos discentes, nem entre as percepções destes e dos servidores técnicos administrativos $(t=0,423)$, tampouco entre docentes e servidores $(t=$ $0,45)$ em relação à preservação do meio ambiente. 
Em outras palavras, o fato de pertencerem a diferentes categorias funcionais não modificou as percepções individuais dos participantes sobre a importância da preservação ambiental. Essa similaridade pode ter sido motivada pela heterogeneidade de sujeitos que compõem cada categoria. Diante dessa constatação, torna-se interessante investigar se atributos pessoais, como sexo e idade, refletem diferenças nas visões individuais acerca da importância da preservação ambiental.

Em relação ao fator sexo, observou-se a predominância das respostas (66,1\% das mulheres e $49 \%$ dos homens) ao item "C: a preservação do meio ambiente é uma pauta urgente, devendo ser prioridade na sociedade atual", assim como observado nas categorias funcionais. Houve maior posicionamento masculino $(45 \%)$ do que feminino $(31,2 \%)$ sobre o item $B$, que afirmava que a preservação ambiental deveria estar equilibrada com 0 desenvolvimento econômico. Comparando as respostas dos participantes dos sexos masculino e feminino com o teste $T$, houve diferença significativa $(t=0,003)$ entre as duas percepções sobre a importância da preservação do meio ambiente, considerando o índice de significância adotado de 0,05 (5\%). A diversidade de percepções individuais é esperada, segundo Gonçalves et al. (2018, p. 2), que afirmam que a compreensão da experiência perceptiva é diferente em cada pessoa uma vez que "as motivações pessoais, as emoções, os valores, os objetivos, os interesses, as expectativas e outros estados mentais influenciam o que as pessoas percebem". As divergências observadas sobre a pauta ambiental podem também estar associadas a abordagens inadequadas da EA, como defendem Pires e Silva (2017). Esses autores associam a concepção majoritária sobre o meio ambiente a uma ecologia conservadora e acrítica, que direciona a solução dos problemas ambientais para as inovações tecnológicas, com pouca reflexão sobre as relações sociais que fundamentam a produção e o consumo desequilibrados.

Agrupando os participantes de acordo com suas faixas etárias, observou-se o posicionamento majoritário pela alternativa "C", exceto entre aqueles com idade inferior a 18 anos, em que a maior parte assinalou o item "D". A percepção apresentada pelos mais jovens aponta para a possibilidade de retrocesso nas visões ambientais desse público e revela a necessidade de incentivos para sua inclusão nas discussões das pautas ambientais. Os resultados do teste T para as faixas etárias estão apresentados na Tabela 1. 
Tabela 1: Resultados do teste T realizado para a comparação das médias das respostas da comunidade acadêmica da UERN de Mossoró (RN) agrupada por faixas etárias sobre a importância da preservação do meio ambiente.

\begin{tabular}{c|c|c} 
Faixa Etária 1 & Faixa Etária 2 & Valor T \\
\hline$<18$ anos & 18 a 34 anos & 0,95 \\
\hline$<18$ anos & 35 a 44 anos & 0,97 \\
\hline$<18$ anos & 45 a 60 anos & 0,87 \\
\hline$<18$ anos & $>60$ anos & 0,72 \\
\hline 18 a 34 anos & 35 a 44 anos & 0,91 \\
\hline 18 a 34 anos & 45 a 60 anos & 0,71 \\
\hline 18 a 34 anos & $>60$ anos & 0,54 \\
\hline 35 a 44 anos & 45 a 60 anos & 0,71 \\
\hline 35 a 44 anos & $>60$ anos & 0,59 \\
\hline 45 a 60 anos & $>60$ anos & 0,47
\end{tabular}

Embora a maioria dos menores de 18 anos tenha demonstrado percepção distinta da observada nas demais faixas etárias, o teste T revelou que não houve diferença significativa na percepção de que a preservação do meio ambiente é uma pauta importante e urgente atualmente de pessoas de diferentes idades. De acordo com Silva e Crispim (2011), a divulgação midiática das informações sobre os problemas ambientais facilita o acesso de pessoas de todos os níveis sociais ao conhecimento dos problemas ambientais, criando um despertar ecológico.

Analisando a percepção da comunidade sobre a importância da preservação do meio ambiente agrupada de acordo com a origem escolar e a renda familiar, obtiveram-se os resultados expressos na Figura 2. Assim como observado em relação às categorias funcionais, sexo e faixas etárias, pessoas provenientes de diferentes redes de ensino e pertencentes a diferentes faixas de renda familiar reconheceram, indistintamente, o item " $\mathrm{C}$ " como o mais adequado. Isso demonstra que o conhecimento sobre a crise ambiental e a imperiosa preservação do meio ambiente tem alcançado a sociedade em geral e que é necessário que o saber coletivo seja capaz de mobilizar a coletividade no sentido de efetivar a proteção ao meio ambiente. 

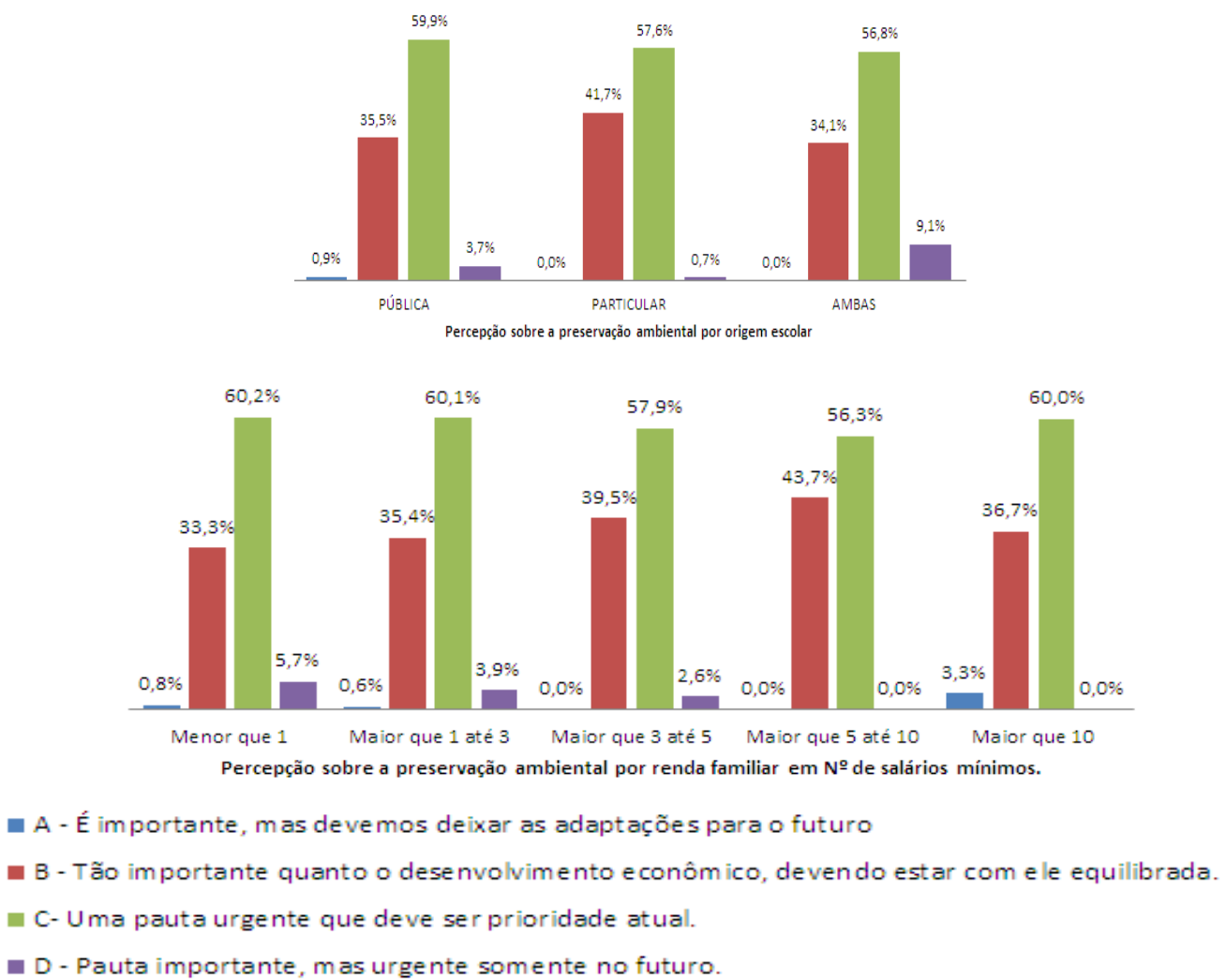

Figura 2: Gráficos representativos da opinião da comunidade acadêmica da UERN de Mossoró, agrupada por origem escolar (acima) e por renda familiar (abaixo), sobre a importância da preservação do meio ambiente, abordada no questionário definitivo aplicado em 2020.

\section{Percepção sobre a Educação Ambiental}

O ponto de vista dos participantes sobre a Educação Ambiental foi aferido a partir da proposição de uma situação hipotética, a saber: "A diretoria de uma escola de ensino básico pretende inserir uma disciplina sobre Educação Ambiental (EA) em sua grade curricular, reduzindo a carga horária das demais matérias, sob o protesto de alguns professores. Em relação a isto...". Foram fornecidas quatro alternativas de respostas, designadas pelas letras $A, B, C$ e $D$, para que os participantes assinalassem a que melhor representasse seu julgamento sobre a situação proposta, conforme a Figura 3. 

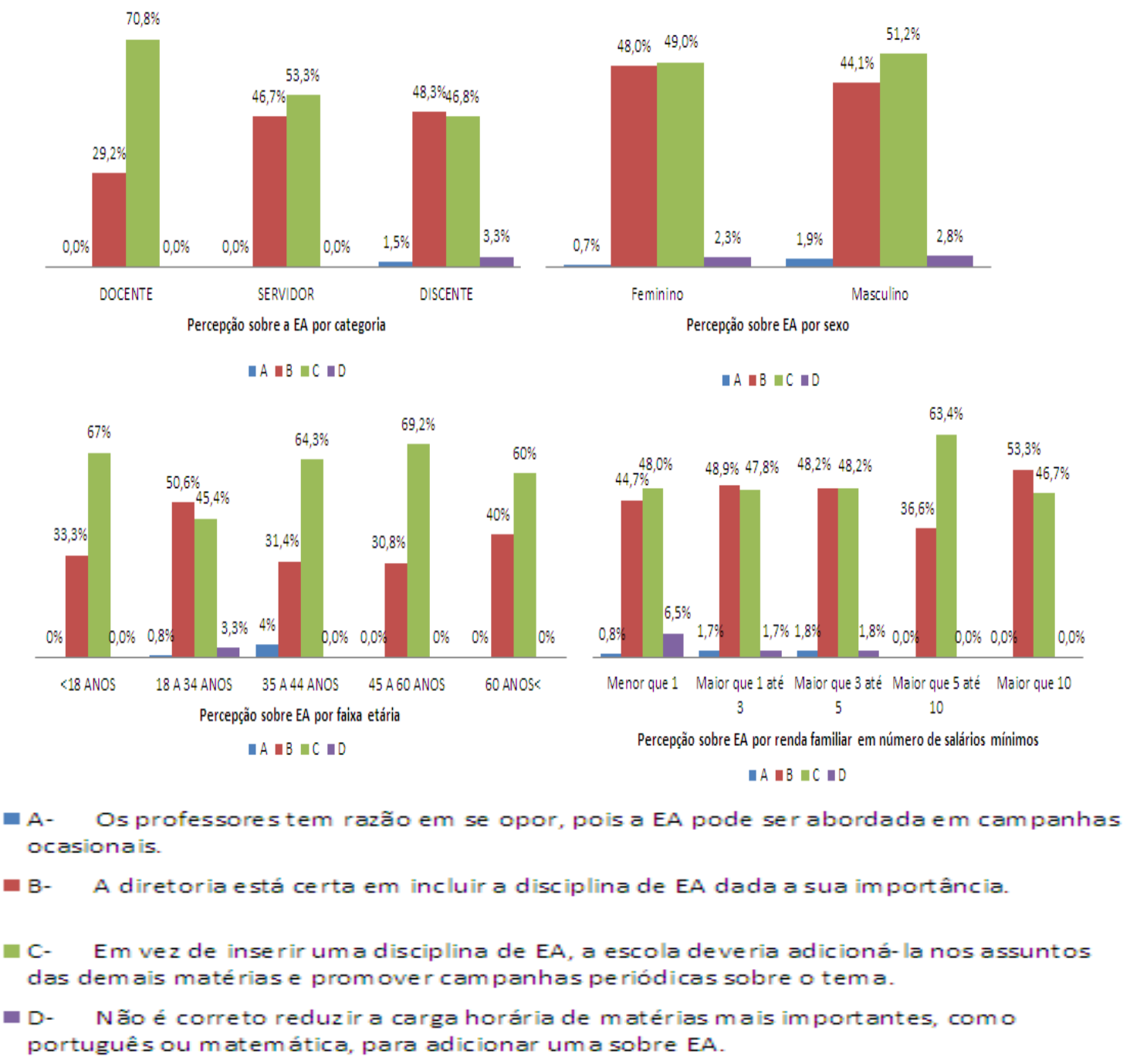

Figura 3: Gráficos representativos do julgamento da comunidade acadêmica da UERN em Mossoró, agrupada por categoria, sexo, faixa etária e renda familiar, sobre a melhor abordagem da Educação Ambiental no ensino.

No tocante à percepção sobre a forma de inserção da Educação Ambiental (EA) no ensino básico, os posicionamentos dos participantes se dividiram principalmente entre as alternativas " $B$ " e " $C$ " para os fatores sexo, categoria funcional, renda familiar e faixa etária, com predominância do item $\mathrm{C}$ na maioria dos casos. Sobre esta pauta, houve diferença significativa entre as percepções de discentes e docentes $(t=0,002)$, em que muitos discentes defenderam a inserção da EA no ensino como uma disciplina específica, enquanto a maioria dos docentes entendeu que a Educação Ambiental deve ser tratada no escopo de todas as matérias e em diversos recursos didáticopedagógicos. Discordando da concepção apresentada pelos discentes, Tavares et. al. (2018, p. 14) citam diversos autores que defendem a abordagem inter e transdisciplinar para a Educação Ambiental. Para estes autores: 
Um dos principais objetivos da Educação Ambiental é promover a transformação social, uma vez que a mesma não acontece só dentro das escolas, mas em todos os espaços da sociedade podendo ocorrer de maneira individual e coletiva com o propósito de formar cidadãos com consciência que seja capaz de se importar com os problemas globais, observando suas causas e inter-relações em uma perspectiva sistêmica, em seus contextos sociais e históricos (TAVARES et. al.; 2018 p.14).

Não houve diferença significativa na percepção de homens e mulheres $(t=0,71)$ sobre esse assunto e nem entre pessoas compreendidas nas seguintes faixas etárias: menores de 18 e a partir de 18 a 34 anos $(t=0,47)$; menores de 18 e a partir de 35 a 44 anos $(t=0,87)$; menores de 18 e a partir de 45 a 60 anos ( $t=0,92)$; menores de 18 e maiores de 60 anos ( $t=0,87)$; a partir de 18 a 34 e maiores de 60 anos ( $t=0,53)$; a partir de 35 a 44 e a partir de 45 a 60 anos $(t=0,46)$; a partir de 35 a 44 e maiores de 60 anos $(t=0,94)$; a partir de 45 a 60 e maiores de 60 anos $(t=0,68)$. A maioria desses, de acordo com a Figura 3, entendeu que a EA é importante e deve ser inserida em todas as atividades de ensino e no assunto das demais disciplinas. Essa constatação favorece a hipótese de que haveria boa aceitação de ações de EA na universidade por parte da comunidade pesquisada.

No entanto, tais iniciativas devem se dar de modo estratégico, como argumenta Layrargues (2014), que considera reducionistas os procedimentos de Educação Ambiental realizados nas escolas ao explorarem, em muitos casos, temas isolados em detrimento de uma reflexão crítica e abrangente sobre os valores culturais da sociedade de consumo, do consumismo, do industrialismo, do modo de produção capitalista e dos aspectos políticos e econômicos da questão ambiental.

A disposição da comunidade acadêmica de participar de determinadas ações de Educação Ambiental foi investigada nos enunciados, cujas respostas estão expressas na Figura 4. Quanto à possibilidade de participarem de capacitações e palestras gratuitas sobre o correto manejo de resíduos, 44,6\% marcaram 10 pontos, correspondentes a "extremamente provável", que somados a outros $15,3 \%$ que marcaram 09 pontos ultrapassam a metade dos respondentes da pesquisa. Sobre essa questão, não houve diferenças significativas entre a postura demonstrada por discentes e docentes $(t=0,30)$, por docentes e servidores $(t=0,78)$ e nem por servidores e discentes $(t=0,38)$, demonstrando que a participação em tais atividades é do interesse de parcela relevante de pessoas pertencentes a todas as categorias. As percepções foram similares também entre homens e mulheres $(\mathrm{t}=0,11)$ e entre indivíduos das diversas faixas etárias abrangidas por este estudo, exceto quando comparadas as percepções dos maiores de 60 anos com os da faixa de 18 a 34 anos $(t=0,001)$ e daqueles com os da faixa de 45 a 60 anos $(t=0,03)$. A diferença na percepção entre os maiores de 60 anos e as duas outras faixas recém mencionadas sobre o interesse na participação nesse tipo de iniciativa reflete a 
necessidade de pesquisas futuras para o desenvolvimento de capacitações mais atrativas para esses grupos, respeitando suas especificidades.

O interesse da comunidade acadêmica em campanhas locais de coleta seletiva se encontra na Figura 4. Observou-se aceitação semelhante à que foi obtida em relação às campanhas e palestras gratuitas sobre o manejo de resíduos, em que $44,8 \%$ assinalaram 10 pontos e $12,6 \%$ marcaram 09 pontos. Sobre essa iniciativa, houve diferença significativa no posicionamento dos discentes em relação aos docentes $(t=0,0003)$ e aos servidores $(t=0,01)$, em que pelo menos $15 \%$ dos discentes assinalou entre zero e cinco pontos, representando a categoria menos engajada nessas ações. Esse dado ressalta a importância do desenvolvimento de práticas político-pedagógicas que incentivem a participação estudantil nesse tipo de campanha, visando o aperfeiçoamento de sua formação como cidadãos ambientalmente conscientes. Houve, ainda, diferença significativa na disposição de homens e mulheres $(t=0,03)$ em participar dessas campanhas, em que as mulheres se mostraram mais interessadas. Os maiores de 60 anos também apresentaram perfil diferenciado em comparação com as faixas de 18 a 34 anos $(t=0,001)$ e de 35 a 44 anos $(t=0,01)$, enfatizando a importância do investimento em ações educativas especialmente voltadas para o público de maior idade.

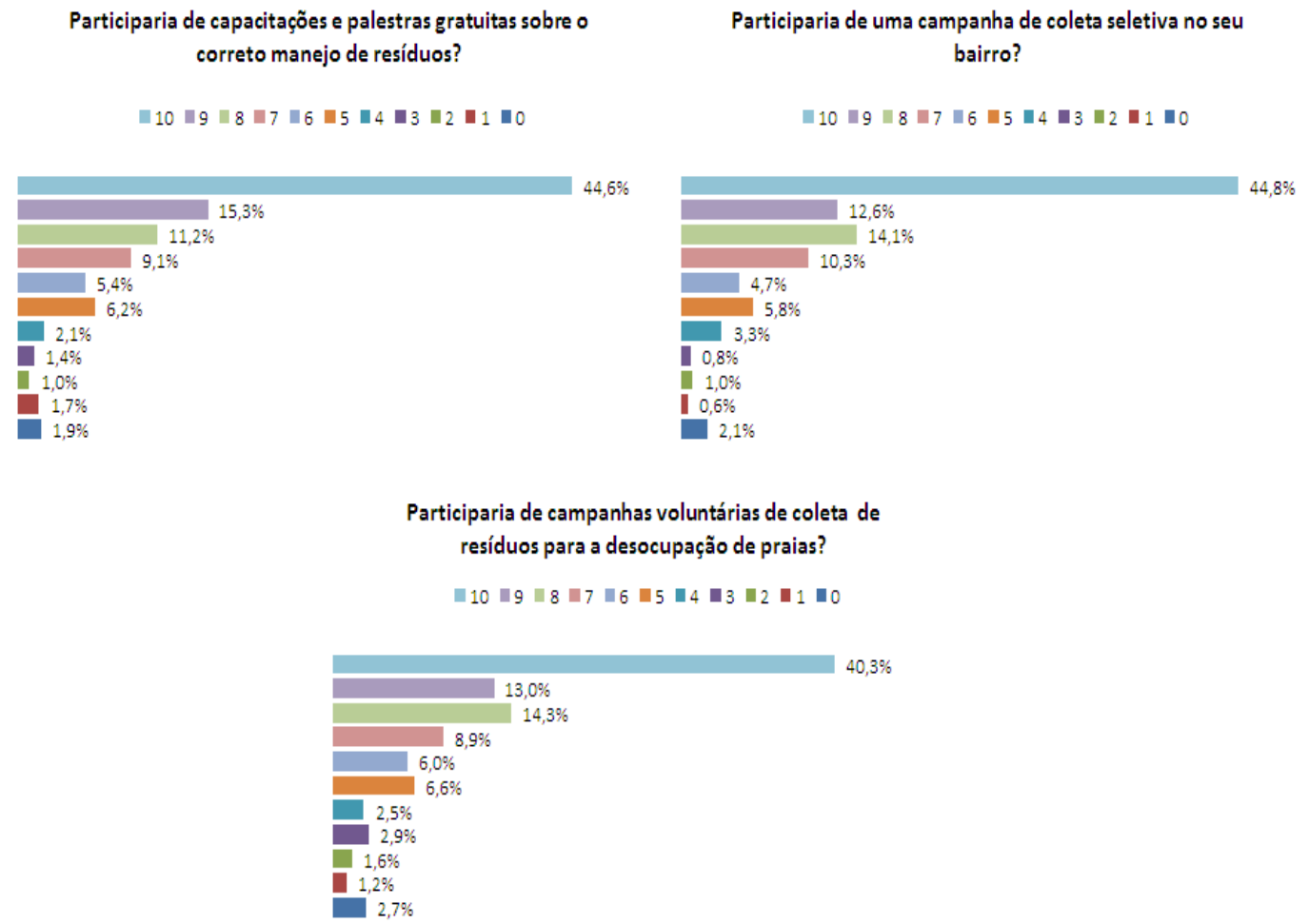

Figura 4: Disposição da comunidade acadêmica da UERN de Mossoró, em uma escala de 0 a 10 pontos, em aderir a três diferentes ações propostas de EA.

Sobre a adesão dos indivíduos a ações de despoluição de praias, a Figura 4 revela que $40,3 \%$ afirmaram haver grande probabilidade de 
participarem, marcando 10 pontos, e outros 13\% mostraram-se altamente engajados, marcando 09 pontos. Nesse tópico, não houve diferença significativa nas posturas relatadas por docentes e discentes $(t=0,50)$, por docentes e servidores $(t=0,60)$ e por discentes e servidores $(t=0,99)$ e nem entre pessoas de idades distintas, porém tal diferença foi identificada entre homens e mulheres $(t=0,003)$, em que $81,6 \%$ das mulheres demonstraram disposição em participar dessas ações, marcando entre 07 e 10 pontos, enquanto $69,2 \%$ dos homens apresentaram a mesma pontuação.

A Educação Ambiental efetiva requer a inclusão da pauta ambiental nas diversas áreas e nos diversos níveis de ensino, pesquisas e nas atividades de extensão universitária. Jacobi (2003 p.190) reafirma este entendimento:

[...] a produção de conhecimento deve necessariamente contemplar as inter-relações do meio natural com o social, incluindo a análise dos determinantes do processo, o papel dos diversos atores envolvidos e as formas de organização social que aumentam o poder das ações alternativas de um novo desenvolvimento, numa perspectiva que priorize novo perfil de desenvolvimento, com ênfase na sustentabilidade socioambiental.

A defesa da abordagem multidisciplinar da Educação Ambiental, por parte considerável dos respondentes, é um incentivo ao desenvolvimento de ações e programas educativos sobre o meio ambiente que capacitem os diversos atores sociais a melhorarem sua relação com o espaço natural.

Se grande parte da comunidade acadêmica demonstrou perceber os princípios que regem a pauta ambiental e se dizem dispostas a proteger o meio ambiente, torna-se necessário avançar no enfrentamento de dificuldades que impeçam o desenvolvimento de práticas sustentáveis por parte dessas pessoas. Entre as dificuldades intrínsecas apontadas por Peixoto e Pereira (2013) estão o comodismo, o desinteresse, a sensação de impotência, a precariedade nas condições financeiras e a falta de incentivo do governo. Para os autores, esses fatores são os principais limitantes da efetivação do comportamento ambientalmente responsável.

\section{Conclusões}

Os dados obtidos neste estudo permitiram concluir que a comunidade acadêmica da UERN, em Mossoró, apresentou percepção adequada em relação a aspectos gerais sobre a preservação do meio ambiente e sobre a Educação Ambiental.

A comunidade universitária, em sua maioria, foi capaz de compreender a importância da preservação ambiental e a urgência na tomada de atitudes para a defesa do meio ambiente. Participantes do sexo masculino, contudo, 
apresentaram maior tendência a crer que, embora urgente, a preservação ambiental deve equilibrar-se com o desenvolvimento econômico.

A importância da Educação Ambiental foi reconhecida por parcela considerável da comunidade universitária, porém foram observadas divergências de percepções sobre a forma mais adequada de inseri-la no ensino. Parte dos discentes apoiou a criação de uma disciplina específica sobre o meio ambiente enquanto a maioria da comunidade defendeu a inserção da Educação Ambiental no âmbito das demais disciplinas, conferindoIhe interdisciplinaridade. Diversos autores apontam a segunda alternativa como a mais eficaz para a incorporação da EA às realidades de pessoas atuantes nas diversas áreas do conhecimento.

A Educação Ambiental foi bem aceita por grande parte da comunidade, que demostrou interesse em colaborar com suas ações, especialmente no que tange aos resíduos sólidos. Essa aceitação deve ser incentivadora para o desenvolvimento de uma EA crítica, participativa e devidamente direcionada abordando-se, em especial, os temas menos compreendidos pela comunidade.

A mudança que o mundo necessita para subsistir diante da crescente degradação do meio ambiente requer que a Educação Ambiental seja capaz de realizar a transição do saber e do desejar para o efetivo agir, combinando o contínuo aprendizado coletivo com a integração de esforços para o alcance da sustentabilidade.

Agradecimentos: À Universidade do Estado do Rio Grande do Norte, ao Programa de Pós-Graduação em Ciências Naturais e à comunidade acadêmica pela participação nesta pesquisa.

\section{Referências}

DILL, M.A; CARNIATTO, I. Concepções de meio ambiente e Educação Ambiental de professores do ensino fundamental I. Revista Brasileira de Educação Ambiental, v.15, n.5, 2020, p.152-172

FERNANDES, R.S et.al. Uso da percepção ambiental como instrumento de gestão em aplicações ligadas às áreas educacional, social e ambiental. In: ENCONTRO DAS ANPPAS, 2., 2004, Indaiatuba. Anais[...] Belém: Associação Nacional de Pós Graduação e Pesquisa em Ambiente e Sociedade, 2004. Disponível em: http://www.redeceas.esalq.usp.br/noticias/Percepcao Ambiental.pdf Acesso em: 19.abr.2021.

GIL, A.C. Métodos e Técnicas de Pesquisa Social. $6^{\underline{a}}$ ed. São Paulo-SP: Atlas, 2008. 
GONÇALVES, J.P et al. Avaliação do nível de conhecimento de uma comunidade acadêmica acerca da coleta seletiva de resíduos. Anais do $18^{\circ}$ Encontro de Engenharia Sanitária e Ambiental - Enasb, e Simpósio LusoBrasileiro de Engenharia Sanitária e Ambiental - Silubesa, Porto: Fundação Dr. Antônio Cupertino Miranda, p 1-8, 2018.

JACOBI, P. Educação Ambiental, Cidadania E Sustentabilidade. Cadernos de Pesquisa, s/v, n. 118, 2003.

LANDIS, J.R.; $\mathrm{KOCH}$, G.G. The measurement of observer agreement for categorical data. Biometrics, v.33, n.1, 1977.

LAYRARGUES, P.P; LIMA, G.F.C. As macrotendências político-pedagógicas da Educação Ambiental brasileira. Revista Ambiente e Sociedade, v.17, n.1, 2014.

LEFF, E. Complexidade, Racionalidade Ambiental e Diálogo de Saberes. Revista Educação \& Realidade, v. 34, n.3, 2009.

PEIXOTO, A.F; PEREIRA, R.C.F. Discurso Versus Ação no Comportamento Ambientalmente Responsável. Revista Gestão Ambiental e Sustentabilidade - GeAS, v. 2, n.2, 2013.

PERCEPÇÃO. Glossário. In: Michaelis Dicionário Brasileiro de Língua Portuguesa. São Paulo: Melhoramentos, 2020.

PINHEIRO, A; SILVA, B. A Estruturação do Processo de Recolha de Dados Online. Actas da X Conferência Internacional de Avaliação Psicológica, Formas E Contextos. Anais [...] Braga : Psiquilíbrios, p. 522-529, 2004. Disponível em: http://repositorium.sdum.uminho.pt/handle/1822/7147 Acesso em: 22 abr. 2021.

PIRES, G.N.; SILVA, M.B.O. Para além do ecologismo conservador: produção destrutiva e intensificação da crise ambiental. Revista Espaço Acadêmico. v.17, n.196, 2017.

RUPPENTHAL, S. et al. Percepção Ambiental: um estudo numa escola pública municipal de Chapecó- Santa Catarina. Revista Educação em Questão, v.56, n.48, 2018.

SAMPIERRE, R. H; COLLADO, C.F; LUCIO, P.B. Metodología de la Investigación. 6ª ed. México: Mc Graw Hill Education, 2014.

SILVA, V.B.; CRISPIM, J.Q. Um breve relato sobre a questão ambiental. Revista GEOMAE - Geografia, Meio Ambiente e Ensino, v. 2, n.1, 2011.

TAVARES, F. B. R; SOUZA, F. C. F; SANTOS, V. E. S. A Educação Ambiental com perspectiva transdisciplinar no contexto da legislação brasileira. Research, Society and Development, v. 7, n.12, 2018. 
TORRINI, D. Questionários online. In: ABDAL, A. et al. Método de Pesquisa em Ciências Sociais: Bloco Quantitativo. São Paulo: CEBRAC-SESC, 2016. Disponível em: http://bibliotecavirtual.cebrap.org.br/arquivos/2017 EBOOK\%20Sesc-Cebrap \%20Metodos\%20e\%20tecnicas\%20em\%20CS\%20\%20Bloco\%20Quantitativo.pdf Acesso em: 22 abr.2021.

TUAN, YI - FU. Topofilia: um estudo da percepção, atitudes e valores do meio ambiente. Londrina-PR: Eduel. 2015.

UERN- UNIVERSIDADE DO ESTADO DO RIO GRANDE DO NORTE. UERN em Números. $\quad[S . \quad$ l. $], \quad 2020$ Disponível em: http://www.uern.br/uernemnumeros/default.asp?item=uern-em-numerosapresentacao Acesso em: 22 abr. 2021.

VASCONCELOS - GUEDES, L; GUEDES, L. F. A. E-surveys: Vantagens e limitações dos questionários eletrônicos via internet no contexto da pesquisa científica. Anais do X Seminário de Administração - FEA-USP. São Paulo, 2007. Disponível em: http://www.ead.fea.usp.br/Semead/10semead/sistema/resultado/an resumo.as p?cod trabalho=420. Acesso em: 22 abr.2021. 